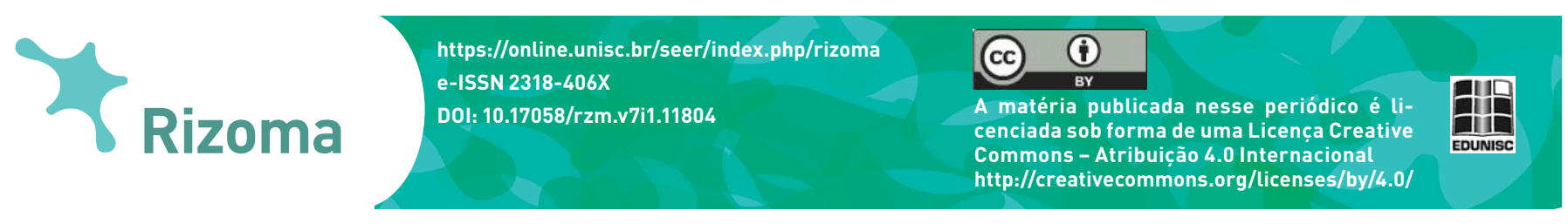

\title{
Os procedimentos críticos de escrita do cineasta italiano Federico Fellini em Veneza, $O$ ator e $O$ inferno
}

\begin{abstract}
Resumo: Traça-se neste artigo a perspectiva autoral crítica do cineasta italiano Federico Fellini que exacerba as fragilidades do cinema diante da televisão e da indústria cultural italiana tendo como fio condutor sua autoficção. Como metodologia, traduziremos e analisaremos parte dos argumentos Veneza, L'Attore e L'Inferno, ditos inéditos e originalmente direcionadas ao projeto Blocknotes di um Regista, projeto cinematográfico patrocinado pela RAI TV. Tais argumentos estabelecem uma arquitetura reveladora de seus procedimentos de escrita para o cinema que fazem crítica a televisão.
\end{abstract}

Palavras-chave: Federico Fellini. Blocknotes di un regista. Cinema de autor.

\section{Los procedimientos críticos de escritura del cineasta italiano Federico Fellini en Venecia, L'Attore y L'Inferno}

Resumen: Se traza en este artículo la perspectiva autoral crítica del cineasta italiano Federico Fellini que exacerba, tal caricatura, las fragilidades del rostro del cine y de la industria cultural italiana teniendo como hilo conductor su autoficción. Como metodología, traduciremos y analizaremos parte de los argumentos Venecia, L'Attore y L'Inferno, dichos inéditos y originalmente dirigidos al proyecto Blocknotes di un Regista, que establecen una arquitectura reveladora de sus procedimientos de escritura para el cine.

Palabras clave: Federico Fellini. Blocknotes di un registro. Cine de autor.

\section{Anna Paula Soares Lemos'}

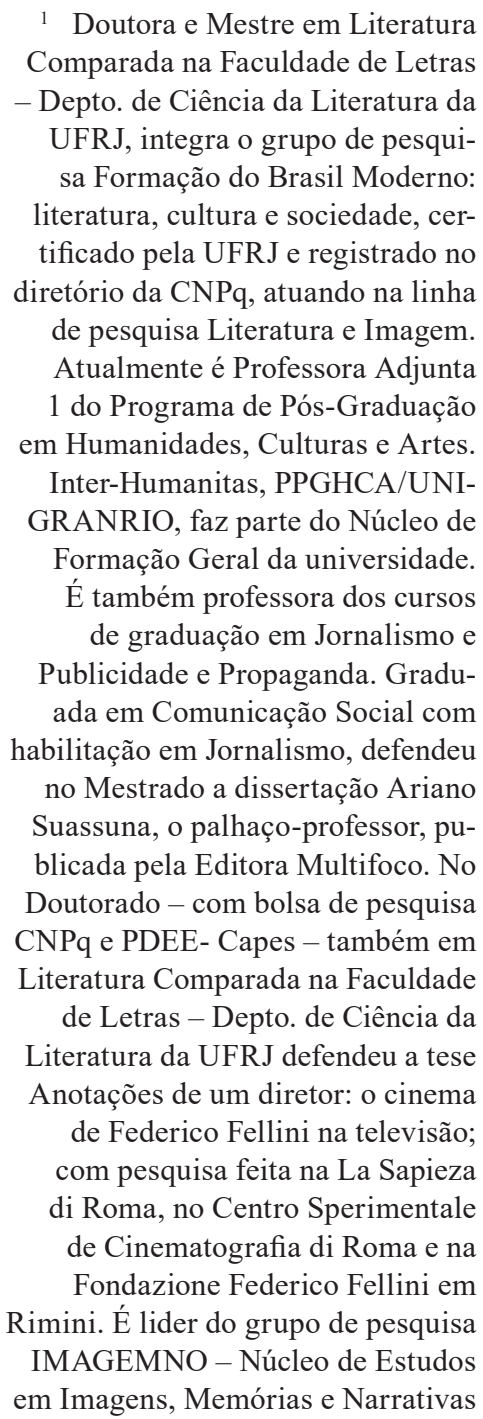

Oníricas. 


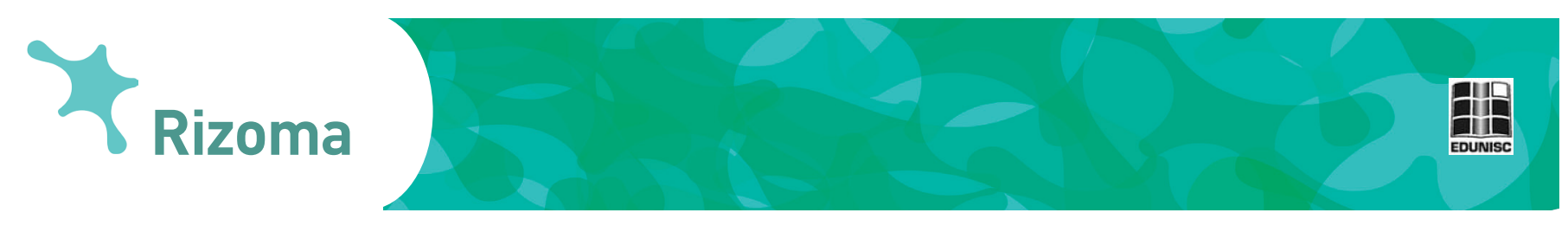

\title{
The critical procedures of writing of the Italian filmmaker Federico Fellini in Venice, L'Attore and L'Inferno
}

\begin{abstract}
In this article the author's critical perspective of the Italian filmmaker Federico Fellini is drawn, which exacerbates the fragility of the face of the cinema and the Italian cultural industry, having as its guiding thread its autofiction. As a methodology, we will translate and analyze part of the arguments Venice, L'Attore and L'Inferno, previously unpublished and originally directed to the project Blocknotes di un Regista, which establishes a revealing architecture of its procedures of writing for the cinema.
\end{abstract}

Keywords: Federico Fellini. Blocknotes di un regista. Author cinema.

\section{Considerações iniciais}

Propõe-se, neste artigo, um caminho de análise e tradução dos argumentos ditos não filmados de Veneza, L'Attore e L'Inferno, do cineasta italiano Federico Fellini, publicados em 1995 no Catálogo Federico Fellini, sob curadoria de Lietta Tornabuoni, como mote para mapear os procedimentos de escrita autoral dos filmes do cineasta. Entende-se que as inspirações autorais de Fellini se constroem tal qual um caleidoscópio, em que fragmentos inspiradores de outros discursos de arte são propostos para releitura tanto na tela do cinema quanto na tela da televisão. Ele se apropria dos dispositivos da indústria cultural e do espetáculo como um campo de forças ambivalente (MELO, 2010), os incorpora como linguagem e alinhava a crítica por dentro do aparato do qual ele mesmo fez parte. Assim, percebe-se que o cineasta se aproxima da indústria em seu artifício crítico ao invés de distanciarse como fizeram os neorrealistas. Cada um dos argumentos propostos entremostra este procedimento criativo que é, dentre outras coisas, auto ficcional.

Antes da publicação de cada roteiro, Lietta Tornabuoni (1995) cita os procedimentos identificáveis em cada uma das construções textuais de Fellini:

Em Veneza, ele escreveu um argumento que tanto serviria a um filme como a uma possível parte da série televisiva Block-notes di um regista. O texto apresenta, além de evocações literárias, imagéticas e problemáticas de Veneza, um testemunhal satírico de Fellini sobre a televisão comercial italiana e o seu maior expoente, Silvio Berlusconi. Em L'Attore, ele faz uma reflexão sobre o mistério e a especial psicologia de um ator. Idealizado ao tom coloquial de um bate-papo com as imagens, o filme traz, 

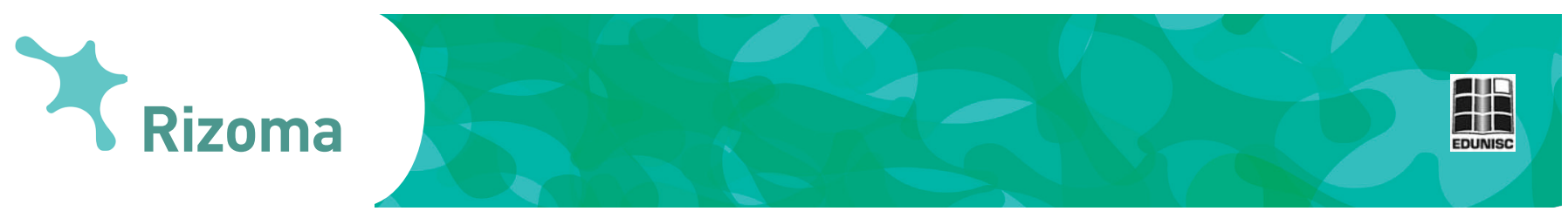

como é frequente em Fellini, elementos autobiográficos e a melancolia do envelhecimento. Já L'Inferno de $A$ Divina Comédia se transforma em um inferno visto por Fellini, assediado por produtores televisivos, americanos e japoneses, que querem uma versão para o cinema do livro de Dante Aliguieri.

Assim, faremos, nesse artigo, a tradução livre e a análise de parte destas anotações do cineasta, que parecem, elas próprias, terem sido citadas e (re) filmadas de forma esparsa nos seus últimos filmes. Será, então, preciso entender quais são os procedimentos de criação na forma (em Veneza), na psicologia do ator (em L'attore) e na crítica infernal à produção de TV (em L'Inferno) - de um autor tão específico e, em certa medida, tão artesanal quanto Fellini.

\section{Sobre as especificidades do "cinema de autor" de Federico Fellini}

Em Inspiring Fellini: literary collaborations behind the scenes, Federico Pacchioni (2014) destaca aqueles que foram fundamentais no processo de criação do cineasta. Ele relembra que Fellini teve como colaboradores alguns dos melhores roteiristas do século XX incluindo Pier Paolo Pasolini, Ennio Flaiano, Tullio Pinelli e Andrea Zanzotto. Destaca, ainda, que a forma como se relaciona com seus atores e, em processo colaborativo, escreve suas cenas, deixa claro o procedimento constante de anotações e montagens no que ele chama de "aqui e agora da filmagem". Em Fare um film, ele deixa claro que o maior erro que um diretor pode cometer é querer adaptar o ator ao personagem: "Eu faço o contrário, me esforço para adaptar o personagem ao ator" (FELLINI, 2004, p. 85).

Então, os argumentos de Fellini são obras abertas que são, no momento da filmagem, regidos por ele como em uma orquestra. Por isso, vale pensar, como base de análise antes de chegar propriamente aos argumentos que serão analisados aqui, em que medida podemos, com a maioria de seus críticos, chamar o cinema de Fellini de um cinema de autor?

\section{O que é um autor?}

No artigo $O$ autor como gesto, Giorgio Agamben (2007) destaca a "função do autor" - expressão criada por Michel Foucault em sua conferência $O$ que é um autor? - para defender uma perspectiva de autoria contemporânea que é o modo de existência e de funcionamento do autor como gesto, como movimento entre outros autores, que não mata o sujeito-autor como alguns acusaram Foucault de fazer em 
sua conferência. Agamben, em sua leitura, dá o seu parecer sobre a função-autor do nosso tempo:

\begin{abstract}
Disso nascem as diferentes características da função-autor no nosso tempo: um regime particular de apropriação, que sanciona o direito de autor e, ao mesmo tempo, a possibilidade de distinguir e selecionar os discursos entre textos literários e textos científicos, aos quais correspondem modos diferentes da própria função; a possibilidade de autenticar os textos, constituindo-os em cânone ou, pelo contrário, a possibilidade de certificar o seu caráter apócrifo; a dispersão da função enunciativa simultaneamente em mais sujeitos que ocupam lugares diferentes; e, por fim, a possibilidade de construir uma função transdiscursiva, que constitui o autor, para além dos limites da sua obra, como "instaurador de discursividade". [...] Nessa perspectiva, a função-autor aparece como processo de subjetivação mediante o qual um indivíduo é identificado e constituído como autor de um certo corpus de textos. (2007, p. 51-52).
\end{abstract}

Neste sentido da função-autor que rearticula um certo corpus de texto que criativamente alinhavado configura um tecido narrativo específico, Fellini faz um cinema de autor.

\title{
4. Fellini, o escritor da tela em sala escura
}

Lietta Tornabuoni (1995), no texto de abertura do catálogo da Mostra Federico Fellini, em que foram publicados os argumentos ditos inéditos que serão analisados neste artigo, destaca os procedimentos de autoria de Fellini:

[...] tinha uma tendência a não atribuir valor algum à filologia, à autenticidade, à cronologia de seu próprio trabalho de roteirista-diretor ou desenhista [...]. [C]om leveza mudava datas, pós-datando e pré-datando desenhos se fosse necessário no momento; manipulava, apagava, reescrevia; se atribuía textos que tinha encarregado outros de fazer; utilizava velhos textos em novos contextos; movia blocos narrativos ou personagens de uma versão para outra do mesmo texto ou de texto para texto, às vezes incluindo escritos de alguém; e ele brincava com quem ficasse chocado com essa facilidade. (TORNABUONI, 1995, p. 17).

Na medida do espetáculo, em estrutura figurativa, expressiva, dilatada, o cineasta lança um olhar crítico, autossuficiente, autoral e desafiador ao mundo da indústria cultural do qual faz parte. Faz do seu estúdio 5, do complexo de cinema Cinecittà, uma "policlínica", uma espécie de hospital que reestrutura as imagens do seu pensamento, 

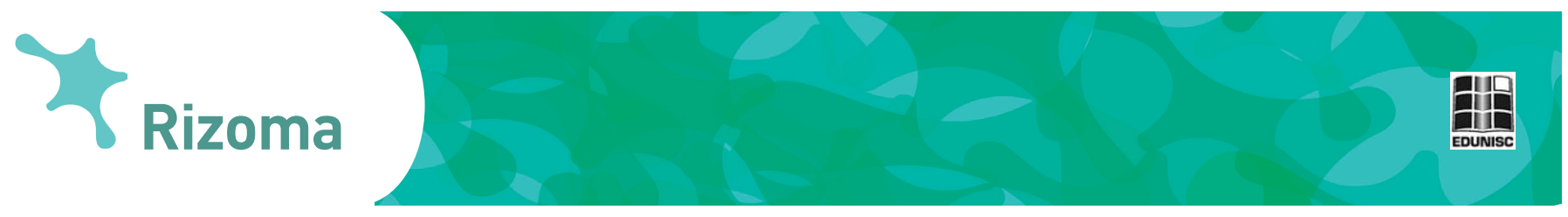

de sua memória, de sua recordação, do seu mundo. Um cuidado artesanal que inicia o processo de reconstrução, desconstruindo, no texto, estruturas pré-estabelecidas. Em detalhados traços e blocos de anotações que estimulam não imagens, mas evocações, e não evocações diretas, mas sentidos, spectrus - cheiros, cores, gostos, sons -, Fellini dilata afetuosamente os fracassos do mundo contemporâneo. O pianista italiano Nino Rota, criador da maioria das trilhas dos filmes de Fellini foi quem mais acompanhou os sentidos do cineasta. Ao trabalhar a trilha de I clowns, por exemplo, Fellini queria uma

\begin{abstract}
...evocação que não fosse assim realisticamente evocativa, que não chamasse exatamente ao circo, mas uma espécie de recordação do circo como se pode imaginar ser a recordação de uma criança. Dou conta agora que isso será um pouquinho difícil, mas é exatamente para seguir esta operação que eu acredito ser bastante erudita do figurativo: dar um perfume da música do circo. Deve ser violenta e fracassada como a música do circo é. Deve permitir ser atenuada, mas sem perder violência.
\end{abstract}

Portanto, a travessia do argumento para o filme, em certa medida, atenua o conflito, mas, ao ter acesso ao texto - que é argumento e não roteiro de Fellini-, percebe-se o peso e a crítica de sua posição de boneco de marionete da indústria cinematográfica, como ele ironicamente se define. Nos últimos filmes, não é possível amenizar a crítica.

\title{
5. Blocknotes di um regista
}

A partir de Blocknotes di un regista, em que, pela primeira vez, ele entra propriamente em cena, se colocando como espelho e agente das suas próprias críticas, o movimento de permissão para atenuar os conflitos fica cada vez mais difícil. Não é mais possível transformar Fellini em um cineasta onírico inofensivo e isso se reflete no seu próprio trabalho, que é propositadamente inautêntico e propositalmente imprevisível. Com não-roteiros, não-atores, nãosequências, não-verdades, o processo inicial é todo ele figura aurática composta de elementos espaciais e temporais que é "a aparição única de uma coisa distante, por mais próxima que ela esteja" (BENJAMIN, 1994, p. 170).

Em uma sequência de formas, o processo de criação cinematográfica de Fellini é todo ele, em cada etapa da filmagem, um ator artesanalmente reprodutor dessa aura. Uma reprodução de aura que Fellini constrói destacando o contraste dos termos: reproduzindo, mas figurando a sombra da aura; reconstruindo e montando, mas destacando em caricatura as fragilidades deste processo. 


\section{$\gamma_{\text {Rizoma }}$}

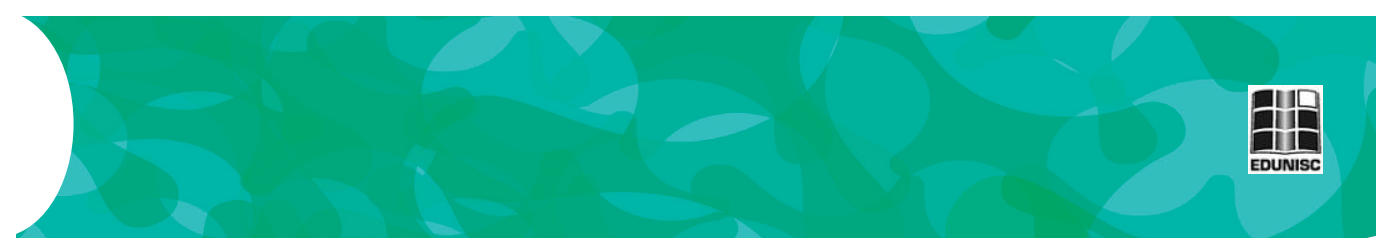

Em L'Attore, nome do seu último roteiro feito para o projeto Block-notes de un regista, em 1992, e que ele não filmou, fica clara essa estrutura quando ele diz que:

\footnotetext{
Este Block-notes eu vou dedicar ao ator, a esta criatura singular que se equilibra entre a realidade e a ficção, ao homem-máscara e à sua jocosa alegria, e também aos seus defeitos, à vaidade, aos aspectos neuróticos, à psicologia por vezes infantil e um pouco esquizoide. (FELLINI apud TORNABUONNI, 1995, p. 24).
}

Além de Il viaggio di G. Mastorna e L'Attore, Fellini tinha também o argumento pronto de Mandrake, Venezia e L'inferno, além de L'Òpera, Cinema Fulgor, L'América e Cinecittà, todos para Blocknotes di um regista. Fellini faz, em cada um dos argumentos, uma espécie de bricolagem de si mesmo; e em cada um dos últimos filmes finalizados, uma bricolagem destes argumentos.

Assim, não é difícil ser cúmplice dos jogos de reconstrução ao falar de sua obra. Um ímpeto de tentar, ainda que como traição da tradução, montar o quebra-cabeças dos seus blocos de anotações: Mastorna e sua viagem pela cidade da morte estão em todos eles, mas principalmente em Ginger e Fred; L'Ópera e Cinema Fulgor, em Roma; Mandrake, L'America e Cinecittà em Intervista. Venezia, L'inferno e L'Attore, escritos contemporaneamente a Intervista, fazem jogo de espelho com I clowns.

Blocknotes di um regista, parte do projeto criado para a TV americana NDC, teve seu primeiro documentário feito em duas versões: uma americana e uma italiana. Trata-se de um filme com média de 40 minutos em que, começando via Il viaggio di G. Mastorna e passando por Satyricon e as cenas não autorizadas do homem do saco de Noites de Cabiria, Fellini parece querer decifrar sua narrativa cinematográfica colocando-se, pela primeira vez, diante da tela como ator do seu próprio cinema. A partir do sucesso de Blocknotes e sem nunca esquecer G. Mastorna, Fellini faz para a TV mais três filmes $-I$ clowns (1970), Roma (1972) e Entrevista (1987) - e, para o cinema, faz um filme em que a TV é protagonista - Ginger e Fred (1984).

\section{Anotações das anotações do diretor: fragmentos dos não filmados}

Os textos inéditos respeitam o nascer, mudar, construir da obra: um primeiro argumento; um tratamento mais amplo e narrado; uma sequência roteirizada; apontamentos sobre o tema, ambientações, personagens; materiais para uma segunda versão. Para este artigo, no entanto, nos interessa o primeiro argumento, e o tratamento mais 
amplo do tema dos não filmados propostos. Todos, veremos um a um, nos puxam pelo pé para dentro do engarrafamento e do aprisionamento do espetáculo.

Em L'Attore, Fellini faz uma homenagem e põe em cena seu duplo Marcello Mastroianni e sua esposa Giulieta Mazina. Trata o ator como uma criatura semi-divina. Como solitário em seu palco e em seu personagem, fala sobre o envelhecimento, sobre o que distingue um ator de um não-ator, sobre o aplauso que é apoteose do ator, sobre o teatro que agoniza na indústria cultural.

\begin{abstract}
A solidão do palco:
Em um clássico teatrinho oitocentesco, destes que se encontram tantos outros em cada cidadezinha italiana, não há viva alma, nenhum guarda, nenhum assistente, ninguém. Rodando pelo prédio Marcello finalmente encontra uma portinha semi-aberta e entra. Mas mesmo internamente o teatro parece desabitado; nada faz pensar que esteja acontecendo um ensaio, uma reunião, um espetáculo em fase de montagem. Andando ao acaso por uma série de pequenas galerias e corredorezinhos se encontra em fim uma plateia, silenciosa e deserta: um imenso pano branco recobre os assentos de veludo como uma grande ressaca, ou um pasto cheio de neve. Os palcos estão vazios e escuros e o lustre lá no alto, no centro do teto, está meio para dentro, meio para fora da sua mansarda. Nenhum ruído a não ser a pingadeira de água nos canos e as gotas de chuva batendo no telhado.

$\mathrm{O}$ ator se move instintivamente pelo palco, gira em volta, desaparece em uma sombra mais escura e, depois de um instante, reaparece no proscênio, iluminado apenas por uma leve luzinha de serviço acesa sabe-se lá onde.

- Mas Federico, onde você me fez vir? Não há ninguém! Aqui faz frio e eu nem jantei...

$\mathrm{Eu}$ poderia perguntar-lhe se gostaria de alguma coisa para comer, mas tenho certeza que Marcello responderia prontamente: -- Não, comer, não! Talvez beber alguma coisa, um aperitivinho... Sabe, se devo interpretar qualquer coisa, ajuda um pouco, um golinho relaxa. (FELLINI apud TORNABUONNI, 1995, p. 25).
\end{abstract}

Tal solidão do palco aparece claramente tanto em I clowns (1970) quanto em Ginger e Fred (1984). Em I clowns, na cena final em que restam as sombras; em Ginger e Fred, na cena em que a luz se apaga em meio à apresentação de Ginger e Fred para a TV. O jogo de luz e sombra é uma constante nos filmes de Fellini, que assume, em muitos dos seus relatos, ser este um artifício utilizado para marcar sua crítica à televisão.

O problema, mostrado em ato por Fellini, é que ninguém mais apaga a luz, ninguém mais fotografa, ninguém mais escreve com a luz. Na televisão, a operação expressionista da luz não é mais 
necessária. Ela trabalha com imagens absolutamente iluminadas, sem os jogos de luz e sombra que, no cinema, são muito cuidadosamente estabelecidos. Nesta medida, a TV - entendida como o olho de vidro do mundo acelerado contemporâneo, produtora de um entendimento parcial e nunca pleno do mundo fragmentado dos acontecimentos - é o objeto de crítica que serve como álibi para questões universais do último Fellini.

Em artigo escrito sobre as impressões do cinema da época, em um dos apontamentos feitos ao seu projeto televisivo Blocknotes di un regista (1968), e depois tomado como inspiração para Ginger e Fred, ele diz o seguinte:

Certo, existe a televisão sarcástica; com a sua correria, a sua voracidade onívora, o seu olho de vidro escancarado sob nosso dia-a-dia como se fosse uma vida paralela e artificial, uma noite em que não se apaga nunca a luz, em que não se sonha nunca. À televisão se vê com a luz acesa, comendo, atendendo ao telefone, com as inquietantes incursões em outros programas, a espiar gostos e frenesis de quem assiste Dynasty e de quem acompanha um concerto. (FELLINI, 1986 p. 86).

Na contemporaneidade criticada por Fellini nos últimos filmes, aquela compreendida entre as décadas de 70 e 90, um esforço de saída é congelar o contexto como nas histórias em quadrinhos, apagar a luz do entorno e voltar o refletor para o ator que, para Fellini, funciona como um ressuscitador - aquele que dá forma aos fantasmas de sua criação. Uma espécie de olhar de infância que é causa natural da poesia. Um olhar que é iluminar, compreender, ver, escolhendo os focos, mapeando os refletores, imitando o real empírico, distribuindo expressões com a luz.

É com olhar de plateia de teatro que Fellini estabelece, em seu cinema, as regras de um jogo consciente com a inconsciência. Um jogo de quebra-cabeças com fotogramas numerados, apagar e acender de luzes, jogo de máscaras circenses e fotografias.

Em L'Inferno, por exemplo, Fellini se coloca, em certa medida, na posição do protagonista Guido Anselmi de 8 1/2 (1963). Figura o inferno de Dante em um "inferno da indústria" e se insere como autômato, como fantoche do processo de produção do filme.

Quantas vezes me ofereceram, insistindo de todo modo, que eu traduzisse em filme a Divina Comédia?

- É uma obrigação que tens, um dever! - Disse, a certo ponto, em uma de tantas reuniões, um dos advogados da CBS que chupava um charuto como se fosse um pirulito (onde estávamos, no Grande Hotel? Em Veneza? Em Cannes? Em Londres?)

Há uma vida que sou seguido, cortejado, ameaçado por 

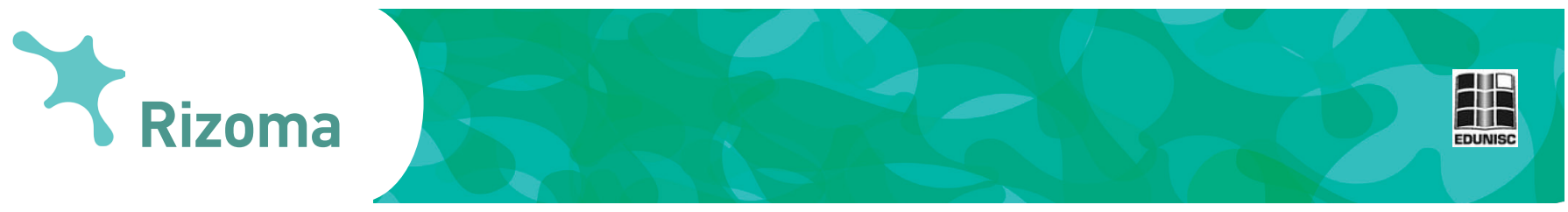

estes clientes extravagantes.

- Não podes recusar, és italiano, Dante é italiano, os americanos te estimam, ainda que eu francamente não tenha entendido nada de nenhum dos filmes de Fellini.

- És um mito, disse uma senhora imitando uma atriz em tom dramático, enquanto o advogado com o charuto, olhandome com pouca simpatia, concluía apressadamente que, em resumo, eu tinha o dever de explicar aos americanos o que Dante foi fazer no inferno. [...] São dois milhões de dólares! [...] E tem uma fila de investidores para este projeto. Senhor Fellini, por que você não aceita? Por que finges rezar?

Mas eu não fingia rezar, ainda que fosse a quinta vez que eu encontrasse presidente, vice-presidente, advogado, investidor [...].

Perdido, confuso, estranho, deitei afundado na poltrona, imóvel, entre os dedos um cálice de champagne: "um fantoche, eu era mesmo um fantoche".

Pronto, exatamente neste ponto da cena, enquanto a minha voz diz esta última palavra, dois operários, que já estavam há tempos em um canto esperando a deixa, segurando um manequim com capa e sapato, poderiam perguntar: -Colocamos ali, doutor?

E, à minha resposta afirmativa, entram em cena e colocam o fantoche Fellini na poltrona, colocando-lhe na mão o cálice.

(FELLINI apud TORNABUONNI, 1995, p. 77)

Neste ponto, Fellini deixa clara a crítica: escolheu um grande fantoche para exprimir "a sensação de impotência, de não pertença, de estranheza que experimenta o autor diante do carrossel infernal de rostos, de lugares, de situações sempre muito envolventes para constranger o fantoche a aceitar o grandioso projeto" (FELLINI apud TORNABUONNI, 1995, p. 78).

Em Veneza, além de mostrar a cidade como uma "invenção teatral", "um produto de fantasia", "um sonho", estabelece um tom de sátira à televisão comercial italiana e o seu maior expoente, Silvio Berlusconi (FELLINI apud TORNABUONNI, 1995, p. 59). Fellini evoca o conto Rendez Vous, de Edgar Allan Poe, para estabelecer essa aura satírica ao filme. Filme a que Fellini pretende dar uma aura fantástica de cidade vista do alto.

E agora, vamos pensar um pouco: Veneza, tudo bem, tem as luzes, as cores, os sons, o nevoeiro, o reflexo do sol, a neve, os palácios, os rios... de acordo, tudo belíssimo, tudo extraordinário, tudo espetáculo, tudo magia, fascínio, fábula, mas e então? O que acontece depois? Os componentes da história, os personagens, quais são? Em uma tentativa vaga, confusa, contraditória de traçar uma linha narrativa para o projeto de filme que pretenda representar a cidade de Veneza, tento sugerir em uma ordem intercambiável uma série de motivos, de pretextos, 

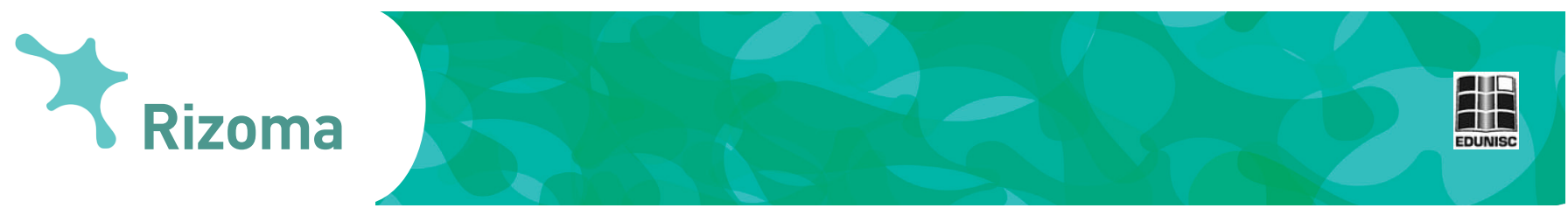

de imagens, de contos que pudessem constituir os capítulos que, por analogia, para continuidade da história, por contraste, por entonação ainda que simplesmente cromática [...] sugerisse no filme a arquitetura de uma história livre [...] Antes que eu me esqueça, gostaria de recordar duas imagens que pudessem sugerir uma impressão fantástica da cidade vista do alto:

a) Do alto. Um indecifrável alfabeto de sinais, hieróglifos, que lembram aqueles sumérios, criam um misteriosíssimo mapa, uma tapeçaria, uma infinita decoração que se estende por centenas de quilômetros e que é criada pela caprichosa, arabesca infiltração de água do mar que entra na terra e, expandindo-se em milhões de tortuosos, curvilíneos canais, rios, laguinhos, sugerem um imenso tapete persa.

b) Lembrar também outra imagem de pequeníssimos cirros brancos como bolas de algodão que navegam a grande profundidade sob a barriga do avião e que iluminados pelo sol projetam a própria sombra como muitas minúsculas flores de pétalas negras na superfície plúmbea do mar. Há muitos anos, li uma história de Poe, poucas páginas, mas jamais ninguém como ele conseguiu representar tão admiravelmente o fascínio triste, fúnebre, surrealista da cidade de Veneza. Aqui, transcrevo a história que me parece chamar "Rendez Vous". Escutem. (FELLINI apud TORNABUONNI, 1995, p. 59).

Em seguida, Fellini transcreve o conto de Poe. Nesta medida, a função-autor que rearticula um certo corpus de texto que criativamente alinhavado configura um tecido narrativo específico, fica mais clara: a bricolagem felliniana que dá um tom de cinema de invenção ao seu cinema de autor.

\section{Considerações finais}

Os roteiros não filmados transparecem a alma de cada um dos filmes filmados por Fellini. Uma escrita em estrutura narrativa de ensaios que funcionam como citações e mesmo como gabaritos de uma forma autoral de cinematografia que se inspira em reflexo na estrutura Neorrealista de contar, porque prioriza a subjetividade e exacerba em caricatura questões típicas da cultura italiana. Mas, também, se afasta do Neorrealismo porque se aproxima da indústria da cultura e do espetáculo do aparato cinematográfico e televisivo para costurar por dentro a crítica.

"Todos os caminhos partem de Cinecittà", diz Gian Piero Brunetta (2007), professor de História e Crítica do Cinema da Universidade de Padova com relação ao Neorrealismo. Todos os caminhos, então, retornam a Cinecittà, no que se refere a Federico 

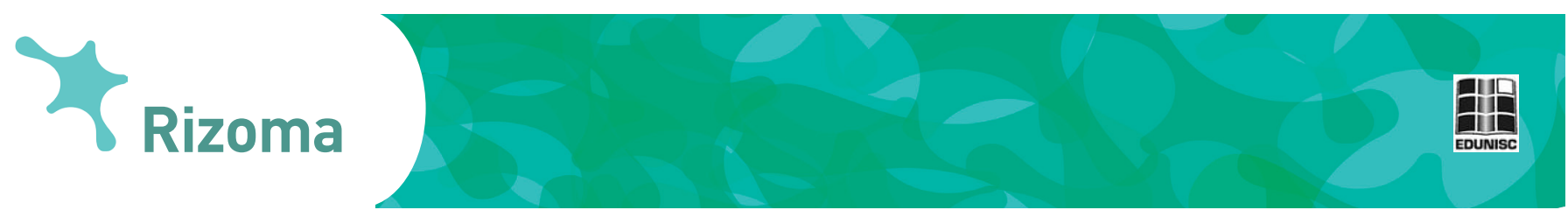

Fellini. Um caminho de inspiração em contraponto, em reflexo. Renzo Renzi, crítico cinematográfico, documentarista e escritor, afirma que Fellini é ele mesmo um espelho: Fellini, então, é um grande, às vezes entusiasmante, espelho. Um espelho de condições de vida deterioradas que ele sabe reviver internamente porque ele mesmo se reconhece nela com seus instrumentos instintivos (RENZI, 1994, p. 9).

Maurizio de Benedictis, professor de História do Cinema na Faculdade de Letras de La Sapienza di Roma, destaca em Fellini uma estrutura narrativa que parte do circo e se assemelha ao mise en abyme:

\begin{abstract}
A Itália de Fellini começa em um pequeno circo que se amplia até o amado Teatro 5 de Cinecittà. [...] Por outro lado, Roma - e dentro dela o microcosmo Cinecittà, que por sua vez traz por dentro o teatro 5 onde se reencontram sua província de partida [Rimini], a capital [Roma] e a Itália toda - é um fervilhar de presenças, rostos e corpos que chegam ao limite do humano em uma cena transformada ou demolida de eventos históricos e naturais. (DE BENEDICTIS, 2010, p. 60).
\end{abstract}

O espelho que, nos termos de Renzi, é Fellini, é, portanto - e também fazendo uma ponte com o que diz De Benedictis -, aquele que explicita a si mesmo como elemento da obra, provocando uma autorreferência ao infinito, tal como vemos em imagens quando estão multiplicadas em espelhos em paralelo. Uma sensação de abismo. Um abismo para o qual o homem é puxado com força pelo pé para o meio do engarrafamento e do aprisionamento terrível que é o espetáculo acelerado da contemporaneidade, como Fellini figura em 8 1/2 (1963).

\title{
Referências
}

AGAMBEN, Giorgio. Profanações. Tradução e apresentação de Selvino J. Assmann. São Paulo: Boitempo Editorial, 2007.

BENJAMIN, Walter. Magia é técnica, arte e política: ensaios sobre literatura e história da cultura. 7. ed. Tradução de Sérgio Paulo Rouanet. Prefácio de Jeanne Marie Gagnebin. São Paulo: Brasiliense, 1994.

BRUNETTA, Gian Piero. Il cinema Italiano contemporâneo: da "La dolce vita" a"Centochiodi”. Roma: Editori Laterza, 2007.

DE BENEDICTIS, Maurizio. Da Paisà a Salò e oltre: parabole del grande cinema italiano. Roma: Avagliano Editore, 2010. 


\section{Yrizoma}

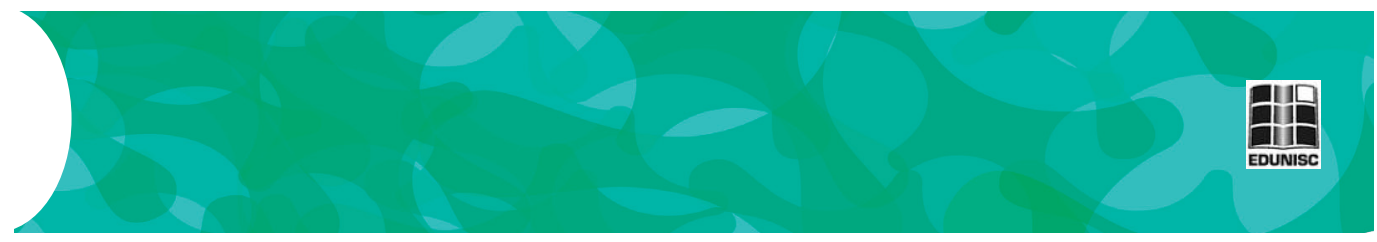

FELLINI, Federico. Fazer um filme. 2. ed. Tradução de Mônica Braga. Rio de Janeiro: Civilização Brasileira, 2004.

FELLINI, Federico. Ginger e Fred. Rendiconto di um film a cura di Mino Guerrini. Sceneggiatura di Federico Fellini, Tonino Guerra e Tulio Pinelli. Milano: Longanesi \& C., 1986.

MELO, Anderson. Poesia e movimento no cinema de Federico Fellini: ensaio sobre arte, mídia e espetáculo. Dissertação de Mestrado. Orientação: Adalberto Müller Junior. Universidade de Brasília - UNB, 2010.

PACCHIONI, F. Inspiring Fellini: literary collaborations behind the scenes. Toronto: University of Toronto Press, Scholarly Publishing Division, 2014.

RENZI, Renzo. L'ombra di Fellini: quarant'anni di rapporti con il grande regista e uno stupidario degli anni Ottanta. Ombra sonora, collana direta di Guido Aristarco. Bari: Edizione Dedalo, 1994.

TORNABUONI, Lietta (a cura di). Federico Fellini. Roma: RCS Libri \& Grandi Opere S.p.A./ Rizzoli, 1995.

\section{Avaliadores: \\ Josmar Reyes \\ Luiza Lusvarghi \\ Demétrio Soster}

